\title{
Oxygen - a limiting factor for brain recovery
}

\author{
Amir Hadanny ${ }^{1,2}$ and Shai Efrati ${ }^{1,2,3,4^{*}}$ \\ See related research by Zhu et al., http://www.ccforum.com/content/19/1/255/abstract
}

\begin{abstract}
Effective brain metabolism is highly dependent on a narrow therapeutic window of oxygen. In major insults to the brain (e.g., intracerebral hemorrhage), a slight decrease in oxygen supply, as occurs in a hypobaric environment at high altitude, has devastating effects on the injured brain tissue. Conversely, increasing brain oxygenation, by the use of hyperbaric oxygen therapy, can improve brain metabolism and its dependent regenerative processes.
\end{abstract}

\section{Introduction}

Intracerebral hemorrhage (ICH) carries significant mortality and morbidity. At high altitude, the prognosis of $\mathrm{ICH}$ is worsened and one of the possible explanations relates to the lower oxygen concentration. In a recent article by Zhu et al. [1], this claim was challenged by exposing minipigs with ICH to hypo-, normo-, and hyperbaric environments. In a hypobaric setting, compared with a normobaric environment, brain tissue oxygenation $\left(\mathrm{PbTO}_{2}\right)$, brain metabolism (lactate, lactate-pyruvate ratio, and glutamate), and neurological scores were significantly worsened. In contrast, a significant improvement in all metabolic parameters was achieved when hyperbaric oxygen was applied, resulting in significant improvement in neurological functions.

\section{Commentary}

From a thermodynamic perspective, the brain is a unique organ in our body. The brain comprises only about $2 \%$ of the body's total weight but uses about $15 \%$ of total cardiac output, $20 \%$ of total oxygen supply, $25-30 \%$ of total body

\footnotetext{
* Correspondence: efratishai@013.net

${ }^{1}$ Sagol Center for Hyperbaric Medicine and Research, Assaf Harofeh Medical Center, Zerifin 70300, Israel

${ }^{2}$ Sackler School of Medicine, Tel-Aviv University, Klachkin 25, Tel Aviv 69978, Israel

Full list of author information is available at the end of the article
}

glucose consumption, and $30 \%$ of total body energy consumption. There is a linear relationship between normal arterial oxygen partial pressure $\left(\mathrm{pO}_{2}\right)$ and $\mathrm{PbTO}_{2}$ [2]. Under normal normobaric conditions, arterial partial pressure of oxygen $\left(\mathrm{paO}_{2}\right)$ is approximately $90 \mathrm{~mm} \mathrm{Hg}$, whereas cerebrovenous $\mathrm{pO}_{2}$ pressure is about $35 \mathrm{~mm} \mathrm{Hg}$. Because oxygen is continuously consumed by the brain, $\mathrm{PbTO}_{2}$ is a continuum with values ranging from $90 \mathrm{~mm}$ $\mathrm{Hg}$, very close to capillaries, to much less than $34 \mathrm{~mm} \mathrm{Hg}$ in more distal regions [2]. $\mathrm{PbTO}_{2}$ values below $15 \mathrm{~mm} \mathrm{Hg}$ indicate ischemia, and values below $5 \mathrm{~mm} \mathrm{Hg}$ indicate brain necrosis.

The minimal $\mathrm{paO}_{2}$ concentrations required for supplying sufficient amounts of intracellular oxygen for effective neurological functioning are unknown. However, we do know that reduction of $\mathrm{paO}_{2}$ to $65 \mathrm{~mm} \mathrm{Hg}$ results in impaired ability of the brain to perform complex tasks. At $55 \mathrm{~mm} \mathrm{Hg}$, short-term memory is impaired, and $\mathrm{paO}_{2}$ of $30 \mathrm{~mm} \mathrm{Hg}$ causes loss of consciousness [2]. Further decrease in $\mathrm{paO}_{2}$ levels may result in tissue infarction, depending on the duration of hypoxia.

Under normal healthy conditions, brain metabolism reaches the upper limit of oxygen consumption, which makes it dependent on cerebral blood flow (CBF). At each time point, the CBF shifts to more active regions (task-dependent) at the expense of other, less active regions. These physiological changes in CBF can be easily seen in functional magnetic resonance imaging. Major insults to the brain, such as ICH, ischemic stroke, or traumatic brain injury, compromise CBF and further decrease the oxygen delivery to the "non-active", injured brain tissue. In a hypobaric environment, oxygen delivery decreases below the minimal metabolic needs. Zhu et al. [1] have shown that in $\mathrm{ICH}$ in a hypobaric environment, when $\mathrm{paO}_{2}$ reached $63-66 \mathrm{~mm} \mathrm{Hg}$ and the diffusion distance for oxygen delivery from microvasculature to brain tissue was expanded because of edema, extravascular blood accumulation, and structural damage of adjacent tissue, the $\mathrm{PbTO}_{2}$ is as low as $9-14 \mathrm{~mm} \mathrm{Hg}$. Consequently, achieving higher tissue oxygen tension and $\mathrm{paO}_{2}$
() Biomed Central

(C) 2015 Hadanny and Efrati. Open Access This article is distributed under the terms of the Creative Commons Attribution 4.0 International License (http://creativecommons.org/licenses/by/4.0/), which permits unrestricted use, distribution, and reproduction in any medium, provided you give appropriate credit to the original author(s) and the source, provide a link to the Creative Commons license, and indicate if changes were made. The Creative Commons Public Domain Dedication waiver(http://creativecommons.org/publicdomain/zero/1.0/) applies to the data made available in this article, unless otherwise stated. 
is crucial for maintaining sufficient oxygenation of the damaged brain tissue.

Clinical studies published this year present convincing evidence that hyperbaric oxygen therapy (HBOT) can be the coveted neurotherapeutic method for brain repair [3-6]. HBOT is a treatment in which oxygen-enriched air (up to $100 \%$ ) is administrated to patients in a chamber where the pressure is elevated above 1 ATA (one atmosphere absolute, which is the ambient atmospheric pressure at sea level). Increasing the plasma oxygen concentration with hyperbaric oxygenation is a potent means of delivering sufficient oxygen to the brain for tissue repair. HBOT might initiate a cellular and vascular repair mechanism and improve cerebral vascular flow [3]. At the cellular level, HBOT can improve mitochondrial function (in both neurons and glial cells) and cellular metabolism, improve blood-brain barrier and inflammatory reactions, reduce apoptosis, alleviate oxidative stress, increase levels of neurotrophins and nitric oxide, and upregulate axon guidance agents. Moreover, the effects of HBOT on neurons can be mediated indirectly by glial cells, including astrocytes. HBOT may also promote neurogenesis of the endogenous neural stem cells. At the vascular level, HBOT was found to have a role in initiation or facilitation of angiogenesis (or both) and cell proliferation needed for axonal regeneration. It is possible that HBOT enables all of the above-mentioned metabolic changes simply by supplying the missing energy/oxygen needed for those regeneration processes.

\section{Conclusions}

In summary, oxygen is crucial for effective metabolism in the brain. As was well proven by Zhu et al., the therapeutic window is very narrow and any slight decrease in oxygen delivery has devastating effects on the injured brain tissue. HBOT may well be the sought-after tool, both effective and simple, for improving $\mathrm{PbTO}_{2}$ and brain metabolism needed for the regenerative processes.

\footnotetext{
Abbreviations

CBF: Cerebral blood flow; HBOT: Hyperbaric oxygen therapy;

$\mathrm{ICH}$ : Intracerebral hemorrhage; $\mathrm{paO}_{2}$ : Arterial partial pressure of oxygen;

$\mathrm{PbTO}_{2}$ : Brain tissue oxygenation; $\mathrm{pO}_{2}$ : Oxygen partial pressure.
}

\section{Competing interests}

The authors declare that they have no competing interests.

\section{Acknowledgments}

The authors thank Raz Tuval for reviewing the manuscript. The authors had no funding sources for writing this article.

\section{Author details}

${ }^{1}$ Sagol Center for Hyperbaric Medicine and Research, Assaf Harofeh Medical Center, Zerifin 70300, Israel. ${ }^{2}$ Sackler School of Medicine, Tel-Aviv University, Klachkin 25, Tel Aviv 69978, Israel. ${ }^{3}$ Research and Development Unit, Assaf Harofeh Medical Center, Zerifin 70300, Israel. ${ }^{4}$ Sagol School of Neuroscience, Tel-Aviv University, Klachkin 25, Tel Aviv 69978, Israel.
Published online: 01 September 2015

\section{References}

1. Zhu HT, Bian C, Yuan JC, Liao XJ, Liu W, Zhu G, et al. Hyperbaric oxygen therapy ameliorates acute brain injury after porcine intracerebral hemorrhage at high altitude. Crit Care. 2015;19:255.

2. Zauner A, Daugherty WP, Bullock MR, Warner DS. Brain oxygenation and energy metabolism: part I-biological function and pathophysiology. Neurosurgery. 2002;51:289-301.

3. Efrati S, Ben-Jacob E. Reflections on the neurotherapeutic effects of hyperbaric oxygen. Expert Rev Neurother. 2014;14:233-6.

4. Boussi-Gross R, Golan H, Volkov O, Bechor Y, Hoofien D, Schnaider Beeri M, et al. Improvement of memory impairments in poststroke patients by hyperbaric oxygen therapy. Neuropsychology. 2015;29:610-21.

5. Efrati S, Fishlev G, Bechor Y, Volkov O, Bergan J, Kliakhandler K, et al. Hyperbaric oxygen induces late neuroplasticity in post stroke patients—randomized, prospective trial. PLoS One. 2013;8, e53716.

6. Boussi-Gross R, Golan H, Fishlev G, Bechor Y, Volkov O, Bergan J, et al. Hyperbaric oxygen therapy can improve post concussion syndrome years after mild traumatic brain injury—randomized prospective trial. PLoS One. 2013;8, e79995. 